\title{
Keeping Fire Apparatus Efficient
}

The Repair, Manufacturing and Test Work of the New York Fire Department Repair Shops

\author{
By Herbert T. Wade
}

IN no form of activity is preparedness a more vital consideration than in the ordinary routine and maintenance of a municipal fire department. In every large city the fire department is on duty twenty-four hours a day, three hundred and sixty-five days in the year, and men and apparatus at all times must be ready to function with 100 per cent. efficiency. Even if there is adequate and available apparatus, there are times in actual service that it must be pushed even beyond its full capacity, irrespective of damage or lack of economy in operation, and with resulting injury. Furthermore, the mobility of fre appatus involve not only convenien and speed in reaching a fre, but aloo danger from breake in ordinary hazards of crowded city streets and bad pavements. At the fire itself it may be operated at overload, damaged by falling walls, or exposed to ice, or eve flames in the case of aerial ladders. Consequently the repair problem is a serious one for a fire department, and its facilities in this direction are in constant demand and often over-taxed.

This, indeed, is the case with the well equipped and organized repair shops of the New York Fire Department, which in addition to making special repairs pos sesses other and important functions. Not only is damaged or worn apparatus repaired, but the ordinary equip ment is kept in shape by this organization and it personnel, while all new apparatus must undergo careful and practical tests in order to ascertain whether it complies with the specifcations under which it is purchased pith the sit is indeed a most seious matter, for failure in fire apparatus at a time of emergency such as a large conflagration may be most disastrous, and the possible breaking down of pumps or motors, or the bursting of hose are not to be lightly regarded, and must be safeguarded against by every means possible. In this connection the technical staff of the repair shop is called upon to assist in the formulation of specifications for the purchase of new apparatus, and they can do this with special intelligence, as its or mization comprises officers of the uniformed as its organization comprises officers of the uniformed force, who have had practical experience in fire fighting
with all types of apparatus. Finally, at the New York with all types of apparatus. Finally, at the New York
Fire Department Repair Shops there is the matter of Fire Department Repair Shops there is the matter of can be made better in a departmental shop than by outside contractors or purchased in the market

It must be borne in mind that within the last ten years there have been radical changes and important developments in fire apparatus. The passing from horse drawn apparatus to motor equipment has been no less striking than the transition from the hand drawn and manual power pumps to the horse drawn steam machines of the past century, and there has also been involved the change from steam to gasoline engines, both for propulsion and for operating the pumps. In many large departments, including that of New York, the transition has been eradual, and to existing steam fire engines some dorm to utilize the pumping

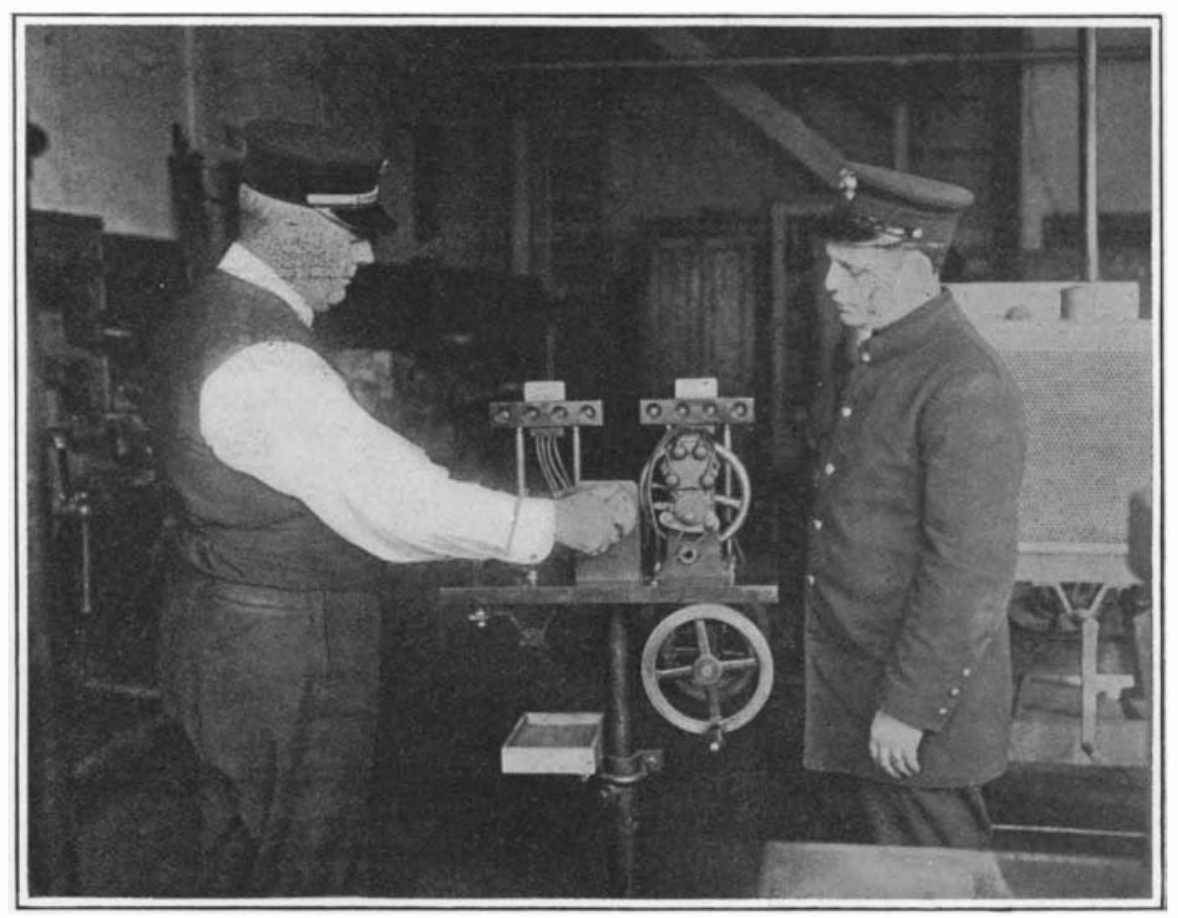

A demonstration of engine operation by the chief of the motor school steam engines on hand, whose functions have been well understood by firemen, and whose reliability has been demonstrated in years of service.

With gasoline propelled vehicles comprising a powerful gasoline motor geared to the wheels, it was of course simply a mechanical problem to supply pumping machinery that could be geared or connected to the main engine when the latter was disengaged from the propelling machinery. At first such combination pumping engines were far from reliable, and the experimental stages were indeed prolonged over severl years, but to-day motor apparatus is highly developed, efficient and reliable, and while it is not fair to say that it is susceptible of no improvement, nevertheless it stands on a reasonably satisfactory basis.

Of course the day of horse drawn apparatus long

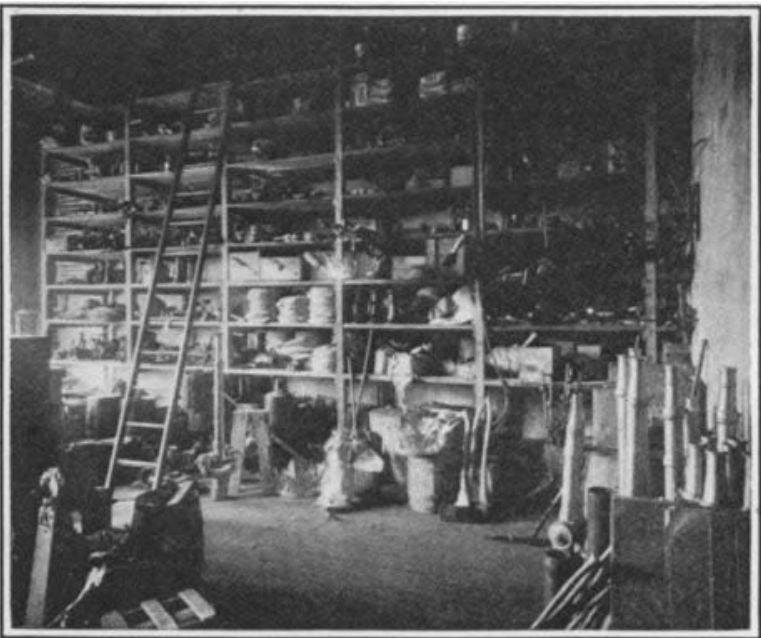

Store room containing some 10,000 different articles and tools

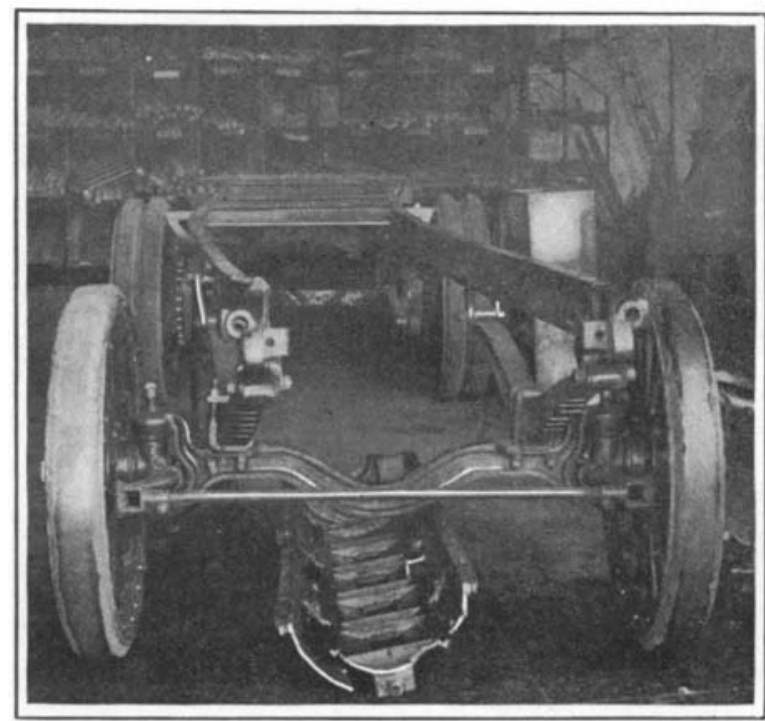

Motor apparatus disassembled for repairs since has passed, and it is only maintained until a suitable motor equipment can be provided, or under exceptional circumstances. In fact, in the city of New York there are 128 motorized engine companies and but 48 remaining to be motorized. With a spare engine required for eng to be motorized. With a spare engine required for every sixth company, there would be 8 additional engine companies, or a total of 56 engines to be motor In addition, there are 7 hose companies, which will have to be equipped with engines on account of increasing conditions of service, so that to-day a total of 63 new engines are required for the city of New York in order to bring its service up to a reasonable standard. Likewise there are 83 motorized truck companies in the city and 28 to be motorized, 12 of which must be city service trucks, and there must be allowed one spare for every sixth piece of apparatus, making a total of 32 trucks required. Further, 4 engine companies now are awaiting motor hose wagons.

These statistics are of interest in connection with the repair shop, not only as stating the requirements of the New York City Fin Department, but as indicating the amount of repairs necessary, as any one with automobile experion subject to various mishaps, and requires more or less atteridance in various mishaps, and requires more or less attendance in the garage or in the machine shop, ranging all the way from actual repairs and rebuilding to minor adjustments, has to take the place of the veterinary, and the apparatus must be properly inspected and maintained in good condition for service.

Consequently the repair shop organization, under Chief Richard J. Marshall, with Chief James Henry, who is in special charge of the motor work and the motor instruction of the firemen, carries on a regular inspection of the motor apparatus in the various fire houses. In addition to passing on questions of operation, replacements and repair, officers of the repair shops attend large fires day and night where repairs may be required, and an emergency crew is always ready for service.

The repair shop, as already noted, has an important function in the testing of apparatus for acceptance, and it may be said that within a year and a half, 15 pumping engines, involving a value of $\$ 150,000$, were rejected as not meeting the specifications. As demonstrating the correctness of this rejection, one of these pumping engines was sold to an adjoining city, and within a short time, according to published statements in the local press, proved a distinct failure in actual service. Likewise in the same period 5 ladder trucks of some $\$ 50,000$ value were also rejected as not complying with specifications, but later, owing to the extraordinary demands for apparatus and the war emergency, several of these were purchased in the open market. As the aerial ladders are employed in removing occupants from burning buildings whose escape is otherwise cut off, their strength and efficiency must be shown beyond question.

The testing of hose is also an important function of the repair shops, and here, as for other equipment and appliances, rigorous specifications are drawn appropriate to the needs of the city, and exceeding the requirements

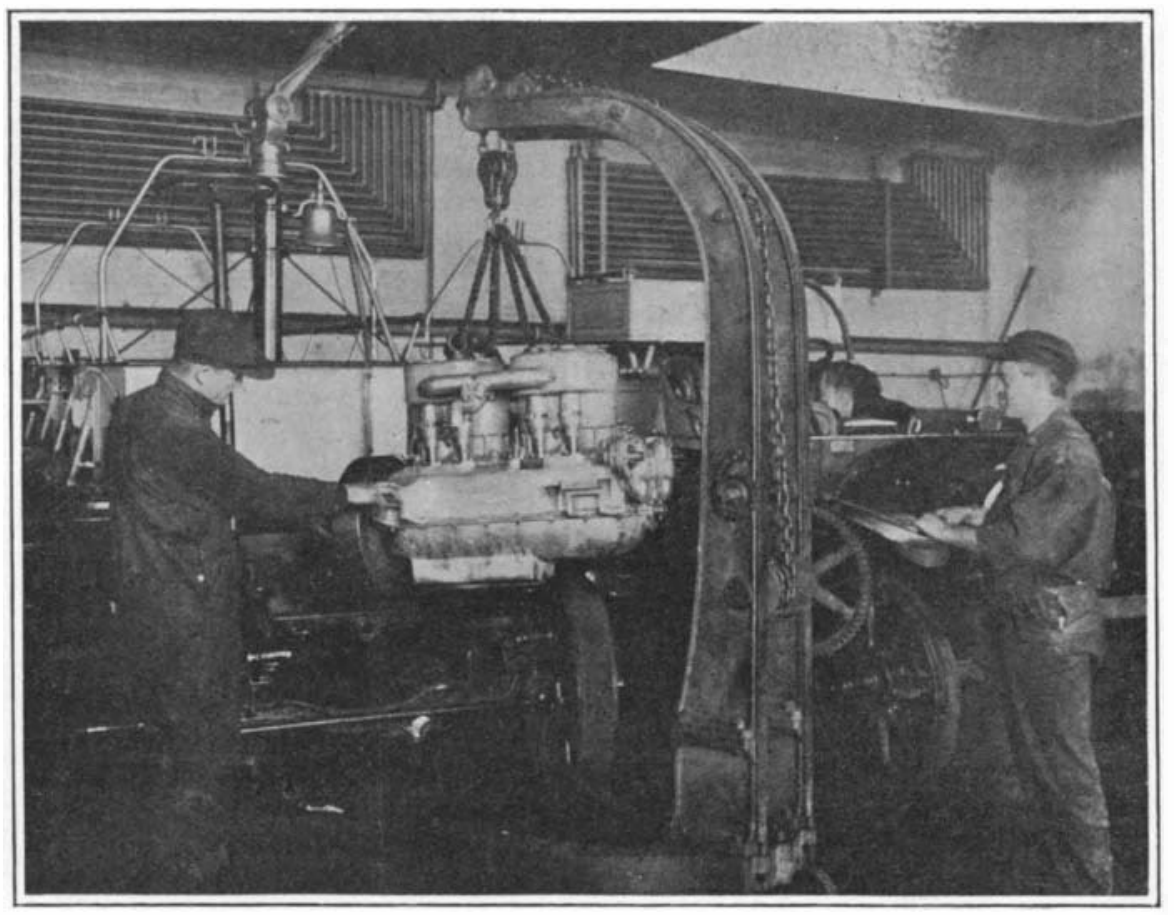

Replacing a rebuilt engine on the chassis of a motor hose wagon 
in many cases set by the National Board of Fire Underwriters. Hose to be accepted by the city of New York under the present specifications must undergo a laboratory test, involving physical and chemical tests of the material and a determination of its ingredients. It receives a hydraulic test of 400 pounds pressure, 20 per cent. of the hose taken at random being actually tested at this amount. The hose supplied is double jacketed hose, and after the outer jacket is removed, the inner jacket is tested at 400 pounds pressure. One length in each lot is tested at 600 pounds pressure. There is also a test for twisting and elongation. The testing of other supplies is also an important branch of the work, especially those furnished by the vendors of materials where rigorous compliance with the specifications is required.

From the engin propelled fire apparatus. This is a matter of great importance, as not only is the city of New York a pioneer in much of this work, but its policy and equipment are looked to by many smaller communities. It must be progressive and carry on a certain amount of experime and the best types cannot be secured unless certain chances are taken and new forms of ma chinery tried out in practice. Since motorization was adopted for the New York City Fire Department, some $\$ 3,000,000$ ha been spent on apparatus that frankly may be considered more or less experimental, but the results, whether they have been positive or negative, have been more than compensating, and the New York Fire Department now knows what to secure as well as what to avoid.

To-day all apparatus undergoes a 12 -hou test, and a pumping engine rated at 700 gallons capacity must maintain that rate for 4 hours against 125 pounds pump gauge pressure, with the engine not exceeding 1100 revolutions per minute, and not developing excessive heat. Such an engine must develop 400 gallons capacity at 200 pounds pump pressure for 4 hours, 320 gallons at 250 pounds pressure for 2 hours, and 200 gallons at 425 pounds pressure for 1 hour, in the case of a piston pump. These pumping tests are made on a city wharf, located as they are on a marginal street facing the Hudson River.

The road test for motor fire apparatus is no less important, and the specifications demand that a test run of 20 miles shal be accomplished over city streets in traffic in one hour with one mile at a speed of 30 miles an hour, to show the flexibility of the motor. To show hill climbing and braking power, tests are made on a 15 per cent grade at which a speed of 7 miles an hour must be made. To test the braking power the apparatus fully equipped must be brought to a stop at three points while descending the hill at speed.

There are in the city of New York 184 engines motorized and 84 truck companies, and 20 spare engines, 18 spare hose wagons and 10 spare trucks are held in readiness for breakdowns. As soon as a piece of for breakdowns. As soon as a piece of pair shop, its place is taken by a spare machine; and the proper adjustment of repairs and the providing of emergency facilities is an important function of the repair shops.

The city of New York has paid heavily for its motor development, and, as in any new stage of mechanical engineering, there have been varying degrees of effciency in the different appliances acquired. Under a system of public bidding, it was found that many assembled machines could be turned over to the city, and these, while furnished cheaper, often increased the maintenance cost, as extra parts were difficult and sometimes impossible to procure. To-day the New York City specifications require that a manufacturer must make his own motor, must have 50 pieces of like type in service, and must be so established that the various in service, and must be so established that the various parts can be secur

These considerations of specifications and tests are interesting in connection with the Repair Shop, to which damaged or defective apparatus naturally returns. The Repair Shop must replace injured parts, irrespective of whether they can be secured from manufacturers or must be developed and made within the shops themselves. Accordingly one important feature of the shops has been the improvement of various features of the motor apparatus in connection with necessary repairs, sometimes involving the re-design and re-making of the motors themselves, and at times the actual construction of an improved motor when failure takes place. Experience showed, for example, in one case that three sets of ball bearings for a crank shaft were preferable to one set of balls and two sets of babbitted bearings, and this modification was adopted for rebuilding engines as required. The shop, with such important replacements and repairs in addition to minor work accordingly has its designing room, a pattern hop, where the hooden pattera are made, a machine shop, finishing and assembly departments. There is a foundry for brass and aluminum, as well as a forge room, but the larger castings, as for engines, are made

has been arranged so that battery troubles can be remedied at an early moment and charged batteries sent out at short notice.

In an adjoining department are the leather shops, where the tops and upholstery of the motor vehicles are now made, and such harness as is in use is repaired, no new harness being purchased.

The wheel shop, several illustrations of which are shown herewith, is an interesting portion of the Repair Shop, as naturally repairs to wheels and the construction of new wheels is an important part of the work for extra wheels must be maintained and damaged wheels must be replaced. The repairs may involve new spokes, felloes, hubs, new metal rims or rubber tires. The test of rubb item of equipment and maintenance, whether on the heavy trucks and pumping engines or on the official cars.

While fire apparatus in appearance has sobered down somewhat from the older days, nevertheless the ornamentation, involving painting, varnishing and nickelplating, still is quite a characteristic, and consequently the paint shop, where repaired apparatus receives its vermilion coats, and the varnish shop, with heat adjustable to a constant temperature, are of interest. Then there is the nickel-plating shop, where various parts are nickel plated, not merely for oxnamentation, as the nickel plating is essential in view of conditions of weather and exposure. This involves not merely the small parts but even the domes of the engines.

In the carpenter shop, situated on the upper floor of the Repair Shop, there is a pattern room, and ladders, both extension and scaling, are made and repaired. Considerable trouble has been experienced in securing straight Oregon pine for ladders, but the stock on hand is carefully kept and seasoned. All ladders for replacements and repairs are made here, though the new trucks are purchased fully equipped.

The test and repair of hose naturally in-
The Wheel Shop. Rebuilding a damaged wheel. Preparing the spokes to receive the felloes volves special machinery and appliances, and our frontispiece shows where a hose coupling is being expanded on the end of a length of hose by hydraulic $p$

Another of our illustrations shows the stores department, where are kept some 10,000 articles available for issue and for minor repairs, many of which are done as well as the more important work.

In examining the new apparatus at the Repair Shop submitted for test or for minor repairs, it was interesting to observe that the city of New York is purchasing no more steam engines, and that motorized pumping engines are now satisfactory for pendent high pressure fire service maintained by New York in congested or high risk territory. Good equipment is now manufactured, and the writer's attention ard type made by a single company that had been in use for 4 years each, and where the total repairs for all had not exceeded $\$ 800$. It was pointed out that the manufacturers of American fire apparatus have now reached a point where they are able to deliver efficient and practical machines that will stand up under the work, and the best apparatus is now supplied by companies that have specialized in this field with all purposes, and especially with the indewas called to 8 engines of a certain standthe most interesting mechanical features of the repair department, and excellent work is done, which is contantly being improved. In this way it has been posible to improve greatly much of the motor apparatus that has been acquired by the department which in some cases began to show wear or failure of parts at as little as 200 miles.

Of course it is impossible at this present stage of development of motor apparatus to standardize everything, but standard apparatus is the aim of the New York Fire Department, and standardized axles and York Fire Department, and standardized axles and wheel can be fitted at once from the supply of spares in case of an accident.

Closely connected with the motor work is a new battery room and charging board, where batteries for the motor apparatus may be rebuilt instead of being purchased, and a delivery system to the various companies outside. The machine shop and assembly rooms possess gineering staffs specially devoted to such machinery, and with the close cooperation of fire engineers from various cities. The better class of material that has been reduced to standard types and practice and made by companies that specialize in fire department needs does not occasion the Repair Shop the trouble caused by the assembled apparatus or experimental types that are able just to meet minimum requirements.

The Repair Shop is also the location of the motor instruction school, where firemen are trained to understand engines and handle motor apparatus, as well as make minor repairs and adjustments under the direction of Chief Henry.

It might be truthfully said that the Repair Shops of the New York Fire Department are a national laboratory of fire appliances, where new apparatus is tested and where service is studied. Much credit for this work is due to Chief John Kenlon, who is the head of the New York Fire Department. 